\title{
Analisis Kualitas Pelayanan dan Kepuasan Pelanggan Menggunakan Metode Servqual (Studi Kasus PT.Balistha Gapala Nandya)
}

\author{
Panji Priya Sahita $^{1, *}$, Julianus Hutabarat ${ }^{2}$, Nelly Budiharti ${ }^{3}$ \\ 1,2,3 Program Studi Megister Teknik Industri, Institut Teknologi Nasional, Malang \\ 65245, Indonesia \\ *Email : panjisahita22@gmail.com
}

\begin{abstract}
Abstrak
Kepuasan pelanggan adalah perbandingan antara kinerja yang diharapkan oleh pelanggan dibandingkan dengan kinerja actual performance dilapangan, PT.Balistha Gapala Nandya perusahaan yang bergerak dalam bidang maintenance elevator ini belum maksimal dalam memuaskan pelanggan, hal ini dapat dilihat dari tingkat keluhan yang diterima perusahaan dari customers. Tujuan dari penelitian ini untuk mengidentifikasi masalah-masalah yang ada dalam pelaksanaan pelayanan jasa maintenance elevator. Maka dari itu perlu dianalisis faktor apa saja yang berpengaruh pada kualitas pelayanan sehingga dapat meningkatkan kepuasan pelanggan sesuai dengan yang diharapkan. Kualitas pelayanan yang meliputi variabel reliability, responsiveness, assurance, empathy, dan tangible, yang dianalisis menggunakan metode servqual untuk mengetahui Gap antara harapan dari customers dan actual performance yang dilakukan oleh perusahaan. Gap terbesar pada variabel tangible sedangkan pada variabel empathy memiliki gap yang positif sehingga dapat diartikan bahwa variabel emphaty telah memenuhi harapan dari customer. Keempat variabel lain harus diprioritaskan dalam perbaikan dan peningkatan kualitas layanan agar dapat memeperkecil gap serta memenuhi harapan customer.
\end{abstract}

Kata Kunci : Gap, Kualitas Pelayanan, Kepuasan Pelanggan, Servqual.

\section{Pendahuluan}

Kualitas pelayanan adalah tingkat layanan yang berkaitan dengan harapan dan kebutuhan pelanggan. Hal ini dapat diartikan bahwa layanan yang diberikan berkualitas jika perusahaan atau lembaga tertentu mampu menyediakan produk atau jasa sesuai dengan keinginan pelanggan [1], [2]. Kualitas pelayanan sangat berhubungan erat dengan kepuasan pelanggan, dimana kualitas pelayanan yang baik akan membuat pelanggan merasa puas dalam menggunakan jasa tersebut [3]. PT. Balistha Gapala Nandya adalah perusahaan yang bergerak dibidang mekanikal elektrikal baik dalam pengadaan, maintenance dan jasa pemasangan unit untuk elevator, escalator, travolator, cargo dan dumb waiter. Tujuan penelitian ini dalam upaya meningkatkan kualitas pelayanan yang diberikan oleh PT.Balistha Gapala Nandya terhadap customer pengguna jasa maintenance elevator agar terciptanya kepuasan dari pelanggan. Berdasarkan data dari perusahaan bahwa terdapat beberapa complaint dari customer mengenai kualitas pelayanan yang diberikan oleh perusahaan jasa maintenanace elevator sehingga para customer pengguna jasa tersebut merasa kurang puas terhadap pelayanan yang diberikan. Keluhan maintenance elevator dapat kita lihat pada Tabel 1 dibawah ini : 
Tabel 1. Keluhan Customer Elevator

\begin{tabular}{|c|l|c|c|l|}
\hline No & \multicolumn{1}{|c|}{ Nama Instansi } & $\begin{array}{c}\text { Jumlah } \\
\text { Unit }\end{array}$ & $\begin{array}{c}\text { Jumlah } \\
\text { Keluhan Per } \\
\text { Tahun 2019 }\end{array}$ & \multicolumn{1}{c|}{ Jenis Keluhan } \\
\hline 1 & RSUD Bangil & 11 & 5 & $\begin{array}{l}\text { Waktu perbaikan yang lama } \\
\text { Ketersediaan Spare part } \\
\text { Respon kurang cepat dalam administrasi } \\
\text { Tenaga kurang profesional } \\
\text { Respon terhadap emergency call }\end{array}$ \\
\hline 2 & RSU Soedono Madiun & 5 & 3 & $\begin{array}{l}\text { Kurangnya pengalaman pada teknisi } \\
\text { Kebersihan kurang } \\
\text { Kerusakan yang berulang }\end{array}$ \\
\hline 3 & RS Paru Jember & 5 & 2 & $\begin{array}{l}\text { Kurangnya respon dalam administrasi } \\
\text { Tenaga kerja kurang profesional }\end{array}$ \\
\hline 4 & RSUD Darsono Pacitan & 5 & 3 & $\begin{array}{l}\text { Waktu perbaikian yang lama } \\
\text { Ketersediaan Spare part } \\
\text { Tenaga kurang profesional }\end{array}$ \\
\hline 5 & $\begin{array}{l}\text { RSUD dr. Sayyidiman } \\
\text { Magetan }\end{array}$ & 5 & 4 & $\begin{array}{l}\text { Kerusakan yang berulang } \\
\text { Respon terhadap masalah kurang cepat } \\
\text { Tenaga kerja kurang profesional } \\
\text { Kesiapan pada alat kerja }\end{array}$ \\
\hline
\end{tabular}

Guna meningkatkan kualitas pelayanan dan untuk mencapainya kepuasan pelanggan maka peneliti melihat beberapa variabel yang berpengaruh terhadap kepuasan pelanggan, yaitu dapat dilihat pada Gambar fishbone 1 dibawah ini [4]:

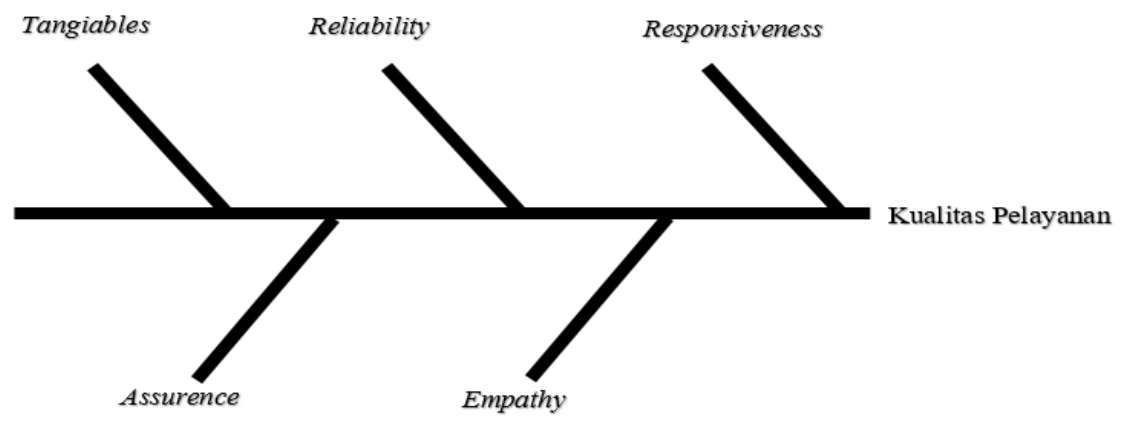

Gambar 1. Fishbone Diagram Kualitas Pelayanan

(Sumber : Kuntoro,2019)

Dari Gambar 1 fishbone dapat diketahu bahwa terdapat 5 variabel yang mempengaruhi kualitas pelayanan jasa maintenance elevator yaitu Reliability, Responsiveness, Assurance, Empathy, dan Tangible [5]-[7] sehingga perlu dilakukannya penelitian pengaruh dari variabel ini terhadap kepuasan pelanggan. 


\section{Metode Penelitian}

Penelitian ini menggunakan jenis data kuantitatif, dan pengolahannya menggunakan metode statistik deskriptif, yakni statistik yang digunakan untuk menganalisis data dengan cara mendeskripsikan atau menggambarkan data yang telah terkumpul sebagaimana adanya [8]. Penelitian ini dilakukan pada lima instansi rumah sakit yang berada di Jawa Timur yaitu RSUD Bangil, RSU Soedono Madiun, RS Paru Jember, RSUD Darsono Pacitan, RSUD Sayyidiman Magetan sebagai konsumen pengguna jasa maintenance elevator. Populasi dalam penelitian ini adalah seluruh karyawan rumah sakit pada objek penelitian serta user unit elevator tersebut. Sampel pada penelitian ini yaitu karyawan pada bagian Instansi Prasarana dan Sarana Rumah Sakit (IPSRS) pada masing-masing instansi rumah sakit tersebut dan user elevator.

Teknik pengumpulan data pada penelitian ini dengan melakukan survey pada masing-masing tempat penelitian sehingga mengetahui bentuk, fisik, karakteristik sesuatu yang akan diteliti [9], [10]. Melakukan observasi untuk mengambil data secara langsung dilapangan untuk mengetahui kondisi pelayanan pada intansi yang menjadi objek penelitian ini dan menyebarkan kuisioner dilakukan untuk mendapatkan data dari pihak customer [11] tentang keluhan pada kualitas yang diberikan jasa maintenance elevator

Instrumen pada penelitian ini adalah kuisioner yang disebarkan kepada instansi-instansi yang menjadi objek pada penelitian ini. Selanjutnya menggunakan Skala Likert sebagai ukurannya yang dapat kita lihat pada Tabel 2 dibawah ini :

Tabel 2. Skala Likert

\begin{tabular}{|c|c|c|}
\hline \multirow{2}{*}{ Pernyataan } & \multicolumn{2}{|c|}{ Skor Jawaban } \\
\cline { 2 - 3 } & Positif & Negatif \\
\hline Sangat Setuju & 5 & 1 \\
\hline Setuju & 4 & 2 \\
\hline Kurang Setuju & 3 & 3 \\
\hline Tidak Setuju & 2 & 4 \\
\hline Sangat Tidak Setuju & 1 & 5 \\
\hline
\end{tabular}

Analisis data pada penelitian ini yaitu penghitungan skor dari hasil kuisioner untuk mengetahui tingkat kualitas layanan guna mendapatkan nilai Gap antar variabel [12] dengan metode servqual sehingga dapat mengetahui dari segi variabel mana yang perlu ditingkatkan.

\section{Analisis Hasil}

Responden dalam penelitian ini sebanyak 75 responden yang berada pada 5 lokasi penelitian yang diambil berdasarkan umur,jenis kelamin, pekerjaan responden yang menjadi sampel dalam penelitian ini.

\section{Uji Validitas}

Validitas menunjukkan sejauh mana suatu pengukuran itu mengukur apa yang ingin diukurnya [13]. Hasil uji validitas actual performance dan harapan dapat kita lihat pada Gambar 2 dan 3 dibawah ini 


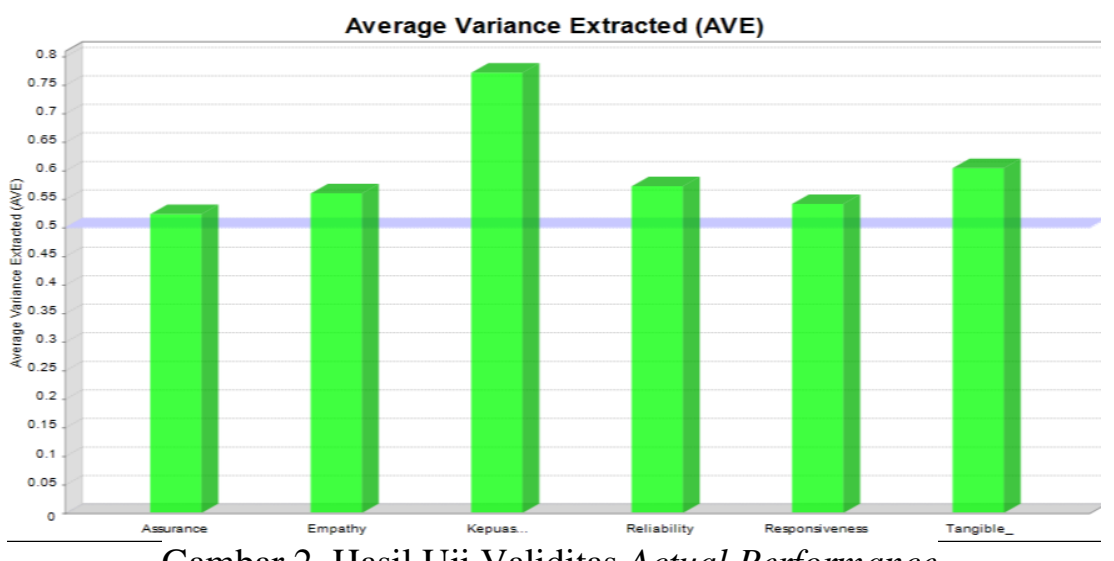

Gambar 2. Hasil Uji Validitas Actual Performance

(Sumber : Data Primer Diolah.2020)

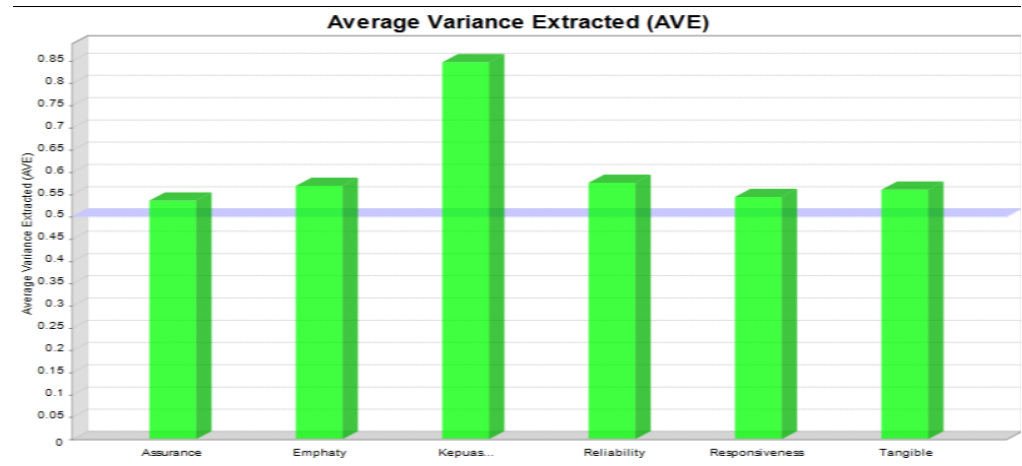

Gambar 3. Hasil Uji Validitas Harapan

(Sumber : Data Primer Diolah.2020)

Gambar 2 dan 3 dapat diketahui bahwa semua indikator dalam kuisioner actual performance dan harapan adalah valid dikarenakan semua nilai pada kuisioner tersebut berada diatas 0,05 (Batas nilai AVE).

\section{Uji Reliabilitas}

Reliabilitas adalah indeks yang menunjukkan sejauh mana suatu alat ukur dapat dipercaya atau diandalkan [14]. Hasil dari uji reliabilitas actual performance dan harapan dapat kita lihat pada Tabel 3 dan 4 dibawah ini :

Tabel 3. Hasil Uji Reliabilitas Actual Performance

\begin{tabular}{|l|c|c|}
\hline \multicolumn{1}{|c|}{ Variabel } & Alpha Cronbach & Keterangan \\
\hline Tangible (Bentuk Fisik) & 0.890 & Reliabel \\
\hline Reliability (Kemampuan) & 0,892 & Reliabel \\
\hline Responsiveness (Daya Tanggap ) & 0,841 & Reliabel \\
\hline Assurance (Jaminan) & 0,770 & Reliabel \\
\hline Empathy (Kepedulian) & 0,805 & Reliabel \\
\hline Kepuasan Pelanggan & 0,890 & Reliabel \\
\hline
\end{tabular}

(Sumber : Data Primer Diolah.2020) 
Jurnal Teknologi dan Manajemen Industri, Vol. 7 No. 1, Februari 2021

Pascasarjana Institut Teknologi Nasional Malang

Tabel 4. Hasil Uji Reliabilitas Harapan

\begin{tabular}{|l|c|c|}
\hline \multicolumn{1}{|c|}{ Variabel } & Alpha Cronbach & Keterangan \\
\hline Tangible (Bentuk Fisik) & 0.862 & Reliabel \\
\hline Reliability (Kemampuan) & 0,893 & Reliabel \\
\hline Responsiveness (Daya Tanggap) & 0,830 & Reliabel \\
\hline Assurance (Jaminan) & 0,781 & Reliabel \\
\hline Empathy (Kepedulian) & 0,802 & Reliabel \\
\hline Kepuasan Pelanggan & 0,955 & Reliabel \\
\hline
\end{tabular}

(Sumber : Data Primer Diolah.2020)

Hasil uji reliabiliti dikatakan reliabel jika nilai dari alpha crocbach melebihi dai 0,7 maka hasil dari uji reliabilitas actual performance dan harapan dapat dikatakan reliabel.

\section{Perhitungan Nilai Servqual}

Perhitungan nilai servqual dilakukan untuk mengukur kualitas layanan yang dilakukan penyedia jasa terhadap harapan dari customer. Dilakukan pengurangan antara actual performance dan harapan customer sehingga memperoleh nilai Gap. Rata-rata Nilai Gap pada penelitian ini dapat dilihat pada Tabel 5 dibawah ini:

Tabel 5. Perbandingan Jumlah Rata-Rata Nilai Gap

\begin{tabular}{|c|l|c|c|}
\hline No & \multicolumn{1}{|c|}{ Variabel } & Jumlah Nilai Gap & Rata-Rata Nilai Gap \\
\hline 1 & Tangibel (Bentuk Fisik) & $-0,51$ & $-0,072$ \\
\hline 2 & Reliability (Kemampuan) & $-0,01$ & $-0,0001$ \\
\hline 3 & Responsiveness (Daya Tanggap) & $-0,38$ & $-0,054$ \\
\hline 4 & Assurance ( Jaminan) & $-0,12$ & $-0,024$ \\
\hline 5 & Empathy (Kepedulian) & 0,23 & 0,046 \\
\hline 6 & Kepuasan Pelanggan & $-0,80$ & $-0,160$ \\
\hline
\end{tabular}

(Sumber : Data Primer Diolah.2020)

Berdasarkan Tabel 5 di atas, maka penilaian tingkat actual performance customer dengan harapan customer untuk variabel tangible, reliability, responsiveness, assurance, kepuasan pelanggan secara keseluruhan menunjukkan nilai servqual yang negatif kecuali variabel empathy yang memiliki GAP positif. Pada variabel empathy yang miliki GAP positif menunjukan bahwa customer yang menggunakan jasa maintenance elevator telah puas akan layanan tersebut sedangkan dari variabel lain yang memiliki GAP negatif menunjukan bahwa perusahaan belum dapat memberikan yang terbaik dari pelayananya kepada customer terutama pada variable tangibel yang memiliki Gap terbesar -0,51.

\section{Kesimpulan}

Kesimpulan hasil dari penelitian yaitu Gap terbesar terdapat pada variabel tangible sebesar -0,50 sehingga perlu dilakukan prioritas perbaikan pada variabel tersebut. Sedangkan pada variabel lain perlu ditingkatkan kembali agar dapat memeperkecil nilai Gap antara actual performance dan harapan dari customer. PT. Balistha Gapala Nandya masih belum mampu memberikan pelayanan yang terbaik sehingga tidak tercapainya kepuasan customer yang dapat dibuktikan dengan selisih nilai GAP negatif antara actual performance dan harapan sehingga diartikan bahwa pelayanan yang diberikan perusahaan kurang puas bagi customer. 
Jurnal Teknologi dan Manajemen Industri, Vol. 7 No. 1, Februari 2021

Pascasarjana Institut Teknologi Nasional Malang

\section{Daftar Pustaka}

[1] V. Farminta, S. Mujiharjo, and K. C. Susena, "Analisis Kualitas Pelayanan Industri Jasa Olah Raga Dengan Menggunakan Metode Servqual dan Importence Performance Analysis (IPA).," J. Agroindustri, vol. 5, no. 1, pp. 57-74, 2015, doi: 10.15900/j.cnki.zylf1995.2018.02.001.

[2] wardhana wahyu. Dharsono, E. Nursati, and J. Hutabarat, "Pengaruh Kualitas Pelayanan Akademik Non Akademik Citra Lembaga Terhadap Kepuasan Dan Loyalitas Mahasiswa (Studi Kasus Di Universitas Satya Wiyata Mandala Nabire," J. Teknol. dan Manaj. Ind., vol. 1, no. 2, pp. 28-35, 2015.

[3] Y. Alaan, "Responsiveness dan Assurance terhadap Customer Statisfaction: Penelitian pada Hotel Selera Bandung," J. Manaj., vol. 15, no. 2, pp. 255-270, 2016.

[4] A. Y. Kuntoro, M. A. Hasan, D. D. Saputra, and D. Riana, "Analisis Faktor-Faktor Yang Mempengaruhi Kepuasan Pelanggan Fixpay Menggunakan SEM Dengan PLS,” J. Inform., vol. 6, no. 1, pp. 122-133, 2019, doi: 10.31311/ji.v6i1.5527.

[5] R. A. Rozandy et al., "Analisis Variabel-Variabel Yang Mempengaruhi Tingkat Adopsi Teknologi Dengan metode Partical Least Square (Studi Kasus Pada Sentra Industri Tahu Desa Sendang, Kec. Banyakan, Kediri)," J. Ind., vol. 1, no. 3, pp. 147-158, 2013.

[6] F. Handoko et al., "Green Industrial System in Indonesia," MATEC Web Conf., vol. 164, pp. 1-7, 2018, doi: 10.1051/matecconf/201816401010.

[7] S. Vigneshwaranp, M. Maranp, and G. Manikandanp, "Impact of TPM Implementation: Literature Review and Direction," IJISET-International J. Innov. Sci. Eng. Technol., vol. 2, no. 12, p. 12, 2015.

[8] D. Astuti and F. N. Salisah, "Analisis Kualitas Pelayanan E-Commerce Terhadap Kepuasan Pelanggan Menggunakan Metode E-Servqual (Studi Kasus : Lejel Home Pekanbaru),” J. Rekayasa dan Manaj. Sist. Inf., vol. 2, no. 1, 2016.

[9] P. Verdika, E. Nursanti, and T. Priyasmanu, "Pengembangan Desain Produk Teh Gelas Dengan Menggunakan Metode Quality Function Deployment Untuk Meningkatkan Penjualan Di CV. Tirta Indo ...," J. Teknol. dan ..., vol. 2, no. 1, pp. 10-14, 2016.

[10] M. F. Perdana, E. Nursanti, and I. Ruwana, "Manajemen Strategi Untuk Meningkatkan Daya Jual Komik Lokal Terhadap Pasar Komik Indonesia," J. Teknol. dan Manaj. Ind., vol. 2, no. 1, pp. 3-9, 2016.

[11] F. K. P. A. Fudholi and B. S. Dharmmesta, "Analisis Pengaruh Kualitas Pelayanan Pada Kepuasan Dan Loyalitas Pelanggan Di Salon Dan Spa," J. Manaj. dan Pelayanan Farm., vol. 4, no. 2, pp. 105-110, 2014, doi: 10.22146/jmpf.274.

[12] P. Deoranto, M. Ulfa, and M. Effendi, "Analisis Pengaruh Experiental Marketing Terhadap Kepuasan Pelanggan Menggunakan PLS DI Duta Katering," in Agroindustri dan Lokarya Nasional, 2015, pp. P6-P14.

[13] N. Utami Handayani, H. Santoso, and A. Ichwal Pratama, "Faktor -Faktor yang memengaruhi Peningkatan Daya Saing Klaster Mebel di Kabupaten Jepara," J. Tek. Ind., vol. 13, no. 1, p. 22, 2012, doi: 10.22219/jtiumm.vol13.no1.22-30.

[14] K. Winarso and M. Jufriyanto, "Analisis Kualitas Pelayanan Internet Indihome Pada Pt. X Dengan Pendekatan Part Least Square," Matrik, vol. 20, no. 1, p. 77, 2019, doi: 10.30587/matrik.v20i1.1017. 